\title{
Antibacterial Activity of Cuttlefish Sepia sp. (Cephalopoda,) Ink Extract
} Against Aeromonas hydrophila

\author{
R Adharyan Islamy* \\ Departement of Aquaculture, Faculty of Fisheries and Marine Science, Brawijaya University Malang
}

\begin{abstract}
Cephalopods ink has shown potential antiretroviral activity. The ink extracts of cuttlefish showed an antibacterial effect. This study aims to investigate the antibacterial activity of the methanolic extract of the ink of cuttlefish Sepia sp. against Aeromonas hydrophila. A. hydrophila are opportunists and associated with aquatic fish and shrimp disease. The shade-dried ink sample from approximately $30 \mathrm{~g}$ ink sacs obtained from 15 animals was immersed separately in methanol $(1: 3 \mathrm{w} / \mathrm{v})$ solvents for overnight. The experiment in this study used the dried extract of cuttlefish ink. The isolate of $A$. hydrophila was originated from Jepara Brackishwater Aquaculture Center. The average yield percentage of cuttlefish ink extract obtained was $4.86 \%$. The results of the MIC test in Table $\mathrm{V}$ show that the highest average absorbance value obtained was at a concentration of $50 \mathrm{ppm}$, which was equal to $1.716 \mathrm{~nm}$, and the lowest absorbance was obtained at a treatment dose of $300 \mathrm{ppm}$ at $0.841 \mathrm{~nm}$, while the Mc Farland tube was $0.933 \mathrm{~nm}$. The results of antibacterial test on Table II showed antibacterial activity of cuttlefish ink extract at negative concentration control showed diameter zone of $5 \pm 1.2 \mathrm{~mm}$, at positive control showed diameter zone of $31 \pm 1.2 \mathrm{~mm}$, at 250 ppm result $19 \pm 0.9 \mathrm{~mm}$, at $300 \mathrm{ppm}$ result $22 \pm 1.4 \mathrm{~mm}$, at $350 \mathrm{ppm}$ result $31 \pm 1.2 \mathrm{~mm}$.
\end{abstract}

Keywords: A. hydrophila; Antibacterial; Cuttlefish Ink; Extract; Sepia sp.

\section{INTRODUCTION}

A. hydrophila is a gram-negative opportunist bacterium associated with aquatic animal disease (Barker, 2001). A. hydrophila causes mass mortalities in several species, including Carps, Snakeheads, Gouramies and Catfishes and is considered as an etiological agent of several diseases such as emaciation, hemorrhagic septicemia, asymptomatic septicemia, ulcerative infection, tail rot and fin rot (Rahman et al., 2001). It also causes Motile Aeromonas Septicaemia (MAS) and Epizootic Ulcerative Syndrome (EUS) as a primary pathogen (Roberts et al., 1993).

The use of antimicrobials that are not as recommended for disease control in human beings and animals has increased the natural emergence of bacterial resistance (Allsop, 1998). The emergence of multiple resistance has dramatically decreased the effectiveness of the antibiotics, mostly. Therefore, searching for novel antibacterial compounds with therapeutic potential for which the pathogens may not have resistance is necessary (Patil et al., 2001).

The Cephalopods classes come under the phylum Mollusca, which involves squid, cuttlefish, octopuses, and nautilus (Voss, 1973). The cephalopods live in all marine habitats and are famous for their defenses, from their fast getting escape movements to changes in coloration that

*Corresponding author: R Adharyan Islamy

Email: r.adhariyan@gmail.com can be disruptive, cryptic, or startling, to arm autotomy, to toxin venom and inking (Hanlon and Messenger, 1996; Normal, 2000). Cephalopod ink has shown potential antiretroviral activity (Rajaganapathi et al., 2000).

Squid and cuttlefish release ink from their ink sac to escape from their predators (Ortonne et al., 1981). The ink extracts of cuttlefish showed antibacterial effect (Nithya et al., 2011; Vennila et al., 2011; Zainab and Abas, 2010; Annaian et al., 2008; Shanmugam et al., 2008). The aim of this study was to analyze the antibacterial activity of the cuttlefish ink Sepia sp. extract against A. hydrophila.

\section{METHODOLOGY \\ Extracts preparation}

Wash the cuttlefish Sepia sp. using sterile water. Then removing the ink sacs by dissections. Squeeze out the cuttlefish sac gently until the ink release. The shade-dried ink sample from approximately $30 \mathrm{~g}$ ink sacs obtained from 15 animals was immersed separately in methanol $1: 3$ $\mathrm{w} / \mathrm{v}$ ) solvents for overnight. The extracts then filtered through the Whatman No.1 filter paper. The filtrate was poured in previously weighed Petri dishes, evaporated to dryness, and the dried extract was used for the experiments.

\section{The yield of Cuttlefish Ink Extract Sepia sp.}

The yield analysis of ink extract based on a comparison of bag weight (containing ink) samples to the weight of the extract of the ink container. 
Table I. Average yield percentage of cuttlefish ink extract

\begin{tabular}{cccc}
\hline Sampel & Weight of ink bag (Gram) & Weight of extract (Gram) & \% yield \\
\hline $\mathbf{1}$ & $5.4 \pm 0,36$ & $0.280 \pm 0.22$ & $5.20 \%$ \\
$\mathbf{2}$ & $5.6 \pm 1,62$ & $0.263 \pm 0.69$ & $4.71 \%$ \\
$\mathbf{3}$ & $4.2 \pm 1,05 \quad$ Average & $0.195 \pm 1.04$ & $4.66 \%$ \\
& & & $\mathbf{4 . 8 6 \%}$ \\
\hline
\end{tabular}

Description: Samples 1, 2, and 3 are replicates

Table II. Minimum Inhibitory Concentration (MIC) test of cuttlefish ink extract (Sepia sp.) on Bacterial growth dan inhibition zone of Aeromonas hydrophilla

\begin{tabular}{cc}
\hline Treatment Dose (ppm) & Absorbance (nm) \\
\hline 50 & $1.716 \pm 0.12$ \\
100 & $1.592 \pm 0.02$ \\
200 & $1.406 \pm 0.01$ \\
250 & $1.148 \pm 0.3$ \\
300 & $0.933 \pm 0.22$ \\
$\mathrm{mcF}$ & $0.841 \pm 0.14$ \\
\hline
\end{tabular}

\section{Bacterial preparation}

The isolate of $A$. hydrophila was originated from Jepara Brackishwater Aquaculture Center. These bacteria were kept in Trypticase Soy Agar (TSA) media at $4^{\circ} \mathrm{C}$ and sub-cultured Trypticase Soy Broth (TSB) overnight before use.

\section{Determination of MIC value}

Minimum Inhibitory Concentration (MIC) is defined as the lowest concentration of a compound /extract/drug that completely inhibits the growth of the microorganism in 24 hrs. Determination of MIC value for the extract that showed high antibacterial activity carried out by the Micro broth dilution method[16].

MIC tests were carried out at doses of $1 \mathrm{ppm}$, 50 ppm, 100 ppm, 150 ppm, 200 ppm, 250 ppm, $300 \mathrm{ppm}$, and mc Farland standard. This test is carried out by inserting a bacterial inoculum of 1 ose into each tube, stored in an incubator at a temperature of $30^{\circ} \mathrm{C}$ to 24 hours. Observe the turbidity in each tube with the degree of turbidity of the media. The spectrophotometer with the wavelength used in A Hydrophilla was $600 \mathrm{~nm}$ to determine the absorbance value of each turbidity at each dose, the smallest concentration which showed no bacterial growth (negative) in the MIC test.

\section{Antibacterial test using Disc diffusion assay}

The analysis of antimicrobial properties was started by dipping a sterile cotton swab into adjusted suspension. The cotton swab was rotated in the suspension and pressed on the wall of the universal bottle to remove excess fluid. The cotton swab with suspension was spread on MuellerHinton agar surface and repeated twice to ensure an even distribution of inoculum. The disc containing antimicrobial compound was pressed on the surface of agar to ensure complete contact. Other discs were placed evenly on the agar surface giving enough surrounding for microorganism inhibition. The petri dish with inoculum and the antimicrobial disc was inverted and incubated at $35 \pm 2{ }^{\circ} \mathrm{C}$ for $24 \mathrm{~h}$. The inhibition zone formed after incubation time was measured and recorded.

\section{RESULT AND DISCUSSION \\ The yield of Cuttlefish Ink Extract Sepia sp.}

Analysis of the yield of ink extracts based on the comparison of bag weight (containing ink) samples to the weight of the extract of the ink produced (Table I).

Based on the table above, it is found that the yield of the bags, respectively, is $5.4 \pm 0.36$ grams; $5.6 \pm 1.62$ grams; and $4.2 \pm 1.05$ grams. Extracts obtained respectively are $0.280 \pm 0.22$ gram; 0.263 \pm 0.69 gram; and $0.195 \pm 1.04$. The average yield percentage of cuttlefish ink extract obtained was $4.86 \%$.

Minimum Inhibitory Concentration (MIC) defined as the lowest concentration of a compound /extract/drug that completely inhibits the growth of the microorganism in $24 \mathrm{hrs}$.

The results of the MIC test in Table II show that the highest average absorbance value was obtained at a concentration of $50 \mathrm{ppm}$, which was equal to $1,716 \mathrm{~nm}$ and the lowest absorbance was obtained at a treatment dose of $300 \mathrm{ppm}$ at 0.841 $\mathrm{nm}$ while the Mc Farland tube was $0.933 \mathrm{~nm}$. 
Table III. The results of antibacterial test

\begin{tabular}{cc}
\hline DOSES (PPM) & INHIBITION ZONE (MM) \\
\hline 250 & $19 \pm 0.9$ \\
300 & $22 \pm 1.4$ \\
350 & $27 \pm 1.6$ \\
Positif & $31 \pm 1.2$ \\
Negatif & $5 \pm 1.2$ \\
\hline
\end{tabular}

the number of bacterial cells can be measured by knowing turbidity or turbidity of the culture; if the culture media becomes turbid, the number of cells will increase (Munfaati et al., 2015). The value of OD can show the amount of light that can be absorbed by the cell-expressed proportional to the number of cells that exist so that it can be interpreted that the higher the concentration of the extract given will increase inhibitory activity. The higher concentration of an antibacterial substance simultaneously increases the antibacterial power (Rahmawati et al., 2015).

Table $\mathrm{V}$ shows that the provision of cuttlefish ink extract. The growth of the $A$. hydrophila decreased as concentration increases. The table above also shows the results of measurements using a spectrophotometer MIC results worth a concentration of $250 \mathrm{ppm}$. It is indicated by the absorbance value of the concentration treatment, which is $0.933 \mathrm{~nm}$, which is smaller than the standard Mc Farland absorbance value of $0.993 \mathrm{~nm}$ while the treatment concentration of $200 \mathrm{ppm}$ with an absorbance value of $1.148 \mathrm{~nm}$ has passed Mc Farland standard. These results indicate that at a concentration of $250 \mathrm{ppm}$, there has been a growth inhibition of $A$. hydrophila.

\section{Antibacterial test}

Antibacterial test concentration used based on the MIC test. In this study using $\mathrm{K}+$ doses (positive control using oxytetracycline antibiotics), 250 ppm, 300ppm 350 ppm, and K- (negative controls without the administration of cuttlefish ink extract Sepia sp. And antibiotics).

The results of antibacterial test on table 2 showed antibacterial activity of cuttlefish ink extract at negative concentration control showed diameter zone of $5 \pm 1.2 \mathrm{~mm}$, at positive control showed diameter zone of $31 \pm 1.2 \mathrm{~mm}$, at $250 \mathrm{ppm}$ result $19 \pm 0.9 \mathrm{~mm}$, at $300 \mathrm{ppm}$ result $22 \pm 1.4 \mathrm{~mm}$, at $350 \mathrm{ppm}$ result $31 \pm 1.2 \mathrm{~mm}$.

The inhibition zone of bacteria increased simultaneity, increasing concentrations of the extract of cuttlefish ink provide valuable information and highlight the potential of this extract in drug development as a candidate source of antibacterial agents being safe and edible.

The results showed that the administration of cuttlefish ink extract Sepia sp. could increase the inhibition zone of $A$. hydrophila bacteria. Treatment with cuttlefish ink extract with a dose of $350 \mathrm{ppm}$ is the best dose. It is indicated by the inhibition zone value that approaches the positive control of treatment. A study states that cuttlefish ink has antibacterial activity (Nair et al., 2011). Several other researchers have also tested antibacterial activity on extracts from cuttlefish ink, the results of which say that the extract has inhibitory activity against several bacteria such as Pseudomonas aeruginosa, Staphylococcus epidermidis, Klebsiella pneumoniae and E. coli (Yuvaraj et al., 2015; Fitrial and Khotimah, 2017). It is presumably because cuttlefish ink has melanin content where melanin itself has antibacterial activity, although it has not been widely revealed. However, the melanin concentration of cuttlefish ink extract $(0.010 \mathrm{~g} / \mathrm{mL})$ was able to kill bacteria so that after 24-hour incubation, there was only one living cell (inhibition reached 99.99\%) (Fitrial and Khotimah, 2017). Besides, Vasantharaja et al. (2014) reported that methanol extracts of Sepia sp. ink using GC-MS showed a mixture of oligomeric structures, which was a combination of dihydroxy indol-2-carboxylic acid and dihydroxyindole. This methanol extract has inhibitory activity, especially against Gram-negative bacteria such as Proteus vulgaris, Pseudomonas aeruginosa, and E. coli. Neifar et al. (2009) reported that dihydroxyindol and dicarboxylic acid from Sepia had microbial inhibitory activity.

Antimicrobial activity of a polysaccharide isolated from the cuttlebone of Sepia aculeate and Sepia brevimana and methanolic extract of the body tissue of Sepia parshadi have been reported (Ramaswamy et al., 2011). The raw ink extract of Chepalopods can be used as bactericidal with a highly significant effect (Fadjar et al., 2016). Studies have shown that methanolic extract of cephalopods showed maximum activity against human pathogens (Ramaswamy et al., 2011). The results obtained that $A$. hydrophila was effectively 
inhibited by the ink extract of cuttlefish Sepia sp.. The extract effect was difference from strain to strain with respective to their concentration.

The ink of cephalopods contains a rich array of chemical secretions to escape from predators (Walters and Erickson, 1986; Caldwell, 2005; Derby et al., 2007) and contains many constituents of aversive compounds (Kicklighter and Derby, 2006; Zhong et al., 2009). There are previous reports on the antibiotic effects of the fluid from the ink sac of cephalopods (Lane, 1992) and the antibacterial activity in the extracts of gill and ink sac of cephalopods (Bayne, 1973). The present study reported that the ink of cephalopods exhibits antimicrobial activity (Sheu and Chou, 1990; Takai et al., 1992). A purified extract of the cuttlefish ink, Sepioteuthis lessoniana is reported to have antibacterial activity against Staphylococcus aureus (Mochizuki, 1979).

\section{CONCLUSION}

The average yield percentage of cuttlefish ink extract obtained was $4.86 \%$. The growth of the A. hydrophila decreased as the concentration increased. MIC test results indicate that at a concentration of $250 \mathrm{ppm}$, there has been a growth inhibition of $A$. hydrophila. It is indicated by the absorbance value of the concentration treatment of 250, which is smaller than the standard Mc Farland as a positive control. The results showed that the administration of cuttlefish ink extract Sepia $s p$. could increase of inhibition zone of $A$. hydrophila bacteria. Treatment with cuttlefish ink extract with a dose of $350 \mathrm{ppm}$ is the best dose. It is indicated by the inhibition zone value that approaches the positive control of treatment.

\section{REFERENCES}

Allsop, A.E., 1998). 'New antibiotic discovery, novel screens, novel targets. and impact of microbial genomics'. Curr opinions. Microbiol. 1, 530-534.

Annaian S., Thangaraj A., Chendur P. G. D., and Thangavel B. (2008). Antimicrobial activity of sulphated mucopolysaccharides (Heparin and heparine like Glycosaminoglycans (GAGs)) from cuttlefish, Euprymna berryi Sasaki, 1929. Trends in Applied Science Research. 3, 97-102.

Barker, G., 2001, Bacterial diseases. In: BSAVA Manual of Ornamental Fish, 2nd Edition (Wildgoose, W.H., ed.), UK.

Bayne, C.J., 1973, Internal defense mechanisms of Octopus dolfeini. Malacol. Rev. 6, 13-17.

Caldwell, R. L. (2005). An observation of inking behavior protecting adult Octopus bocki from predation by green turtle (Chelonia mydas) hatchlings. Pac. Sci., 2005; 59: pp. 69-72.

Derby, C.D., Kicklighter, C.E., Johnson, P.M., and Zhang, X. (2007). Chemical composition of inks of diverse marine mollusks suggests convergent chemical defenses. J. Chem. Ecol, 2007; 33(5): pp. 1105- 1113.

Fadjar, M., Andajani, S., \& Zaelani, K. (2016). Squid (Loligo edulis) ink raw extract as an antivibriosis substance in grouper (Epinephelus fuscoguttatus) juvenile culture infected by Vibrio alginolyticus. AACL Bioflux, 2016; 9(2): pp. 422-428.

Fitrial, Y., \& Khotimah, I. K. (2017). Antibacterial Activity of Melanin from Cuttlefish and Squid Ink. Jurnal Pengolahan Hasil Perikanan Indonesia, 20(2), 266.

Hanlon, R.T. \& Messenger J.B., 1996, Cephalopod behavior. Cambridge University Press, Cambridge. 1996. pp. 232.

Kicklighter, C.E. \& Derby, C. D. (2006). Multiple components in ink of the sea hare Aplysia californica are aversive to the sea anemone Anthopleura sola. J. Exp. Mar. Biol. Ecol, 2006; 334: pp. $256-268$.

Lane F.W., 1962, Economic. In: Kingdom of the octopus, the worlds of science (ecology) pyramid publication, New York, 181-201.

Mochizuki, A., 1979, 'An antisepic effect of cuttle fish ink'. Bull. Jap. Soc. Sci. Fish., 11, 1401 -14.

Neifar A, Rebah FB, Gargouri AF, Abdelmouleh A. 2009. Physicochemical characterization of Sepia officinalis ink and the effects of storage conditions on the coagulation process. Journal of the Marine Biological Association of the UK. 89(04): 803-807.

Nithya M, Ambikapathy V., and Panneerselvam A., (2011). Effect of pharaoh's cuttlefish ink against bacterial pathogens. Asian Journal of Plant Science Research. 49: pp. 49-55.

Nkere, C.K., and Iroegbu, C. (2005)., Antibacterial screening of the root, stem and stembark extracts of Picralima nitida., Afri J of Biotech. 4 (6) (2005) pp. $522-526$.

Norman, M.D., 2000. Cephalopods. A World Guide. Conch Books, Hackenheim, Germany 2000, pp. 172.

Ortonne J.P., Voulot C., Khatchadourian C., Palumbo A., and Prota G. 1981). A reexamination of melanogenesis in the ink gland of cephalopods. In: Pigment cell. Phenotypic Expression in Pigment cells M.Seiji. Ed.) University of Tokyo Press, Tokyo. 1981. pp. 49-57.

Patil, R. G. J., Shanmugam S.A., \& Shakila J.R., 2001. 'Control of bacterial pa-thogens, associated with fish diseases, by antagonistic marine 
actinomycetes iso-lated from marine sediments'. Indian J. Mar. Sci. 1, 264-267.

Rahman, M.M., Wahed, M.I.I., Biswas, M.H., Sadik, G.M. \& Haque, M.E., 2001. 'In Vitro Antimicrobial Activity of the Compounds of Trapa Bispinasa Roxb', Sci 1, 214-216.

Rajaganapathi J., Thyagarajan S.P., and Patterson Edward J.K., 2000, Study on cephalopod's ink for antiretroviral activity. Indian Journal of Experimental Biology. 2000. 36: pp. 583587.

Ramaswamy P., Subhapradha N., Srinivasan A., Shanamugam V., Krishnamoothy J., and Shanmugam A. (2011). In vitro evaluation of the antimicrobial activity of methanolic extract from selected species of cephalopods on clinical isolates. African Journal of Microbiology research, 2011.5: pp. 3884-3889.

Ramaswamy P., Vino A.B., Saravanan R., Subhapradha N., Shanamugam V. and Shanmugam A. (2011). Screening of antimicrobial potential of polysaccharide from cut Lane FW (1962). Economic.In: Kingdom of the octopus, the worlds of science (ecology) pyramid publication, New York, pp. 181-201tlebone and methanolic extract from body tissue of Sepia prashadi Winkworth, 1936. Asian Pacefic Journal of Tropical Biomedicine, 2011, pp 244-248.

Rios, J.L., Recio, M.C., and Villar, A. (1988). Screening methods for natural products with antimicrobial activity: a review of the literature. J Ethnopharmacol leaflets 23 (1988) pp. 127-149.

Roberts, R.J., Frerichs, G.N. \& Miller, S.D., 1992, In: Diseases in Asian Aquaculture. I. Fish Health Section. Edited by Shariff M., Subasinghe R.P., and Arthur J.R., Asian Fish. Soc., Manila, 1992, pp. 431-436.

Shanmugam A, T.S Mahalekshmi, \& Barwin Vino A., 2008, Antimicrobial activity of Polysaccharide Isolated from the Cuttlebone of Sepia aculeate and Sepia brevimana. An Approach to selected antimicrobial activity for human pathogenic microorganisms.
Journal of fisheries and aquatic science, 2, 268-274.

Sheu T.Y., \& Chou. C. C., 1990, 'Antimicrobial activity of squid ink'. J. Chin. Agric. Chem. Soc., 28: pp. 59-68.

Takai M., Kawai Y., Inoue N. \& Shinano H., 1992, 'Comparative studies on microbiological andchemical characteristics of IkaShiokaraakazukuri and Ika- Shiokara Kurozukuri'. Bull. Jpn Soc. Sci. Fish. 58, 2373 $-2378$.

Vasantharaja D, Ravitchandirane V and Anandan V. 2014. Anti-microbial activity and spectrochemical investigation of ink extracts of Sepiella inermis (Van Hasselt 1835). Notulae Scientia Biologicae. 6(3):273-275.

Vennila R., Rajesh Kumar R.K., Kanchana S., Arumugam M., \& Balasubramanian T. 2011, Investigation of antimicrobial and plasma coagulation property of some molluscan ink extracts: Gastropods and cephalopods. African Journal of Biochemistry and Research. 5, 14-21.

Voss, G.L., 1973, Cephalopod resources of the world. FAO Fisheries Circular 149: 75.

Walters, E.T., and Erickson, M.T. (1986). Directional control and the functional organization of defensive responses in aplysia. J. Comp. Physiol. A., 1986; 159: pp. 339-351.

Yuvaraj D, Suvasini B, Chellathai T, Fouziya R, Ivo Romauld S and Chandran M. 2015. Antibacterial studies on the difference body parts of Loligo duvauceli. Journal of Chemical and Pharmaceutical Research. 7(6):406-408.

Zainab D. D., \& Ali Tahar A., 2010. Antimicrobial activity of some crude marine Mollusca extracts against some human pathogenic bacteria. Thi-Qar Medical Journal (TQMJ). 4, 142-147.

Zhong, Guang W., Jiang-Hua S., Jiang-Qiu P., Kun Li, Yan H., \& Hua-Zhong L., 2009, 'Protective effects of Squid ink extract towards hemopoietic injuries induced by cyclophosphamide'. Mar. Drugs., 1, 9-18. 